\title{
DENTAL ASSISTANTS IN THE TEAMWORK
}

\author{
Krassimira Yaneva-Ribagina, Cvetelina Antonova \\ Department of Dental Public Health, Faculty of Dental Medicine, Medical Uni- \\ versity, Sofia, Bulgaria.
}

\section{SUMMARY:}

Purpose: The aim of the study was to establish the socio-demographic and professional characteristics of the sample of dental assistants and their contributions to the efficiency of dental teamwork.

Material and methods: An anonymous inquiry was conducted among 108 dental assistants working in dental offices in 4 Bulgarian cities. The questionnaire consisted of 18 questions about socio-demographic and professional characteristics of the sample and their opinion about obligations, positives and negatives in the workplace, and efficiency of teamwork. The methods used in the survey were sociological (poll) and statistical (alternative analysis).

Results: The socio-demographic and professional characteristics of the surveyed dental assistants were established, such as: gender and age distribution, work in active working age/pension, types of working places, location of practices, types of education and number of dentists working with over the period of their work experience. All respondents reported that they assisted the physicians in the treatment process and the majority of them (70.37-85.19\%) cleaned, disinfected and sterilized the instruments, the workplace and the premises of the practice. Only $4.6 \%$ dealt financial relations with the patients and worked directly in their mouths. The opinion of the respondents for building a well-functioning dental team was that both the personal and professional qualities of the team members were essential.

Conclusions: Dental assistants were convinced of the benefits of their assistance; between $79.6 \%$ and $58.3 \%$ of them believed that they had contributed for quicker and better job of the doctor and to patient's comfort.

Keywords: dental assistants, dentists, cooperation,

\section{INTRODUCTION}

In a historical aspect, the individual practice of dentists has been increasingly transformed into teamwork. Team work and co-operation between healthcare professionals influence the outcomes of higher quality care and work satisfaction.

For the first time in the history of dentistry, the American dentist Dr Edmund Kells operated with support staff in 1885. The practice of Dr Ed. Kells has thrived so much that he needed to hire an assistant - "Lady in Attendance" - Malvina Querria. She is considered the first dental assistant in the modern history of dentistry. [1]

In 1960, the term "4-Handed Dentistry" was introduced during the Conference "Training of dentists for using an assistant to the chair" in order to reduce the stress and the fatigue of the operator. [2]

In 1968 Glen Robinson summed up the concept of "Four Handed Dentistry". It includes a coordinated work of the dentist and the dental assistant as a team. [2]

The names of the auxiliary staff in the dental practice have varied over the years, and in 1977 the WHO adopted a classification for auxiliary staff: [3]

1. Auxiliary staff not directly working with patients:

- Dental Chairside Assistant (Nurse), Dental technician, Oral Health Educator.

2. Auxiliary staff, directly working with patients:

- Dental Hygienist, Denturist, Therapist, Orthodontic Operating Auxiliary.

The teamwork in dental practice improves the quality of the service, increases the working capacity of the dental practitioner, reduces the duration of the manipulations, and improves the organization of the workplace. According to a report from the University of Michigan, in a team with one nurse, the dental practitioner's capacity grew by $35.8 \%$ and with two nurses - by $68.8 \%$. [4] European studies showed that the additional assistant increased productivity and reduced stress by 20-22\%. [5]

In Bulgaria, most of dentists work independently, and there are few practices with more than one assistant. $[6,7]$

\section{PURPOSE OF THE STUDY}

The present study aims to establish the socio-demographic and professional characteristics of the sample of dental assistants and their opinion on their duties and contribute to the teamwork and the main factors supporting to the establishment of an well-functioning dental team.

\section{MATERIAL AND METHODS}

Respondents: An anonymous pilot survey was conducted among 108 dental assistants working in dental offices in the Bulgarian cities of Sofia, Plovdiv, Lom, Kozloduy. The survey tool was an anonymous questionnaire form, with 18 closed, open and mixed questions, which were personally completed. The voluntary self-filling of the questionnaire, according to ethical norms, was 
a form of individual informed consent for the participants to participate in the survey.

Material: The questionnaire provided information on the socio-demographic (No. 1, 2, 3, 4) and professional characteristics of the sample (No. 5,6,7,8,9), the respondents' opinion on positive and negative aspects of teamwork, professional satisfaction and efficiency of teamwork (No. 10-18). Some of the questions were closed, with fixed answers - No. 1, 2, 3, 4, 5, 6, 7, 9, 12, 13, 14, question No. 8 was open, and other questions were mixed - No. 11, $15,16,17,18$ - with fixed answers and blank spaces for writing other answers (Annex 1 - Questionnaire form).

Data Processing: The present study was a pilot survey of a dissertation thesis named "Teamwork in Dental Practice". The poll was conducted among dental assistants working in dental practices in Bulgarian cities of Sofia, Plovdiv, Lom and Kozloduy in the period November 2018 - March 2019. The survey was approved by the Ethical Committee of Medical University, Sofia - Approval No. 1772/19.04.2019.

Methods: The methods used were sociological anonymous inquiry and statistical - alternative analysis. We calculated the maximum permissible error $(\Delta)$, defining the confidence interval at the coefficient value $t=1.96$.

\section{RESULTS}

The dental assistant's profession was more widely practised by women $(103-95 \%)$ than by men $(5-5 \%)-$ this result is shown in fig. 1:

Fig. 1. Distribution of dental assistants by gender

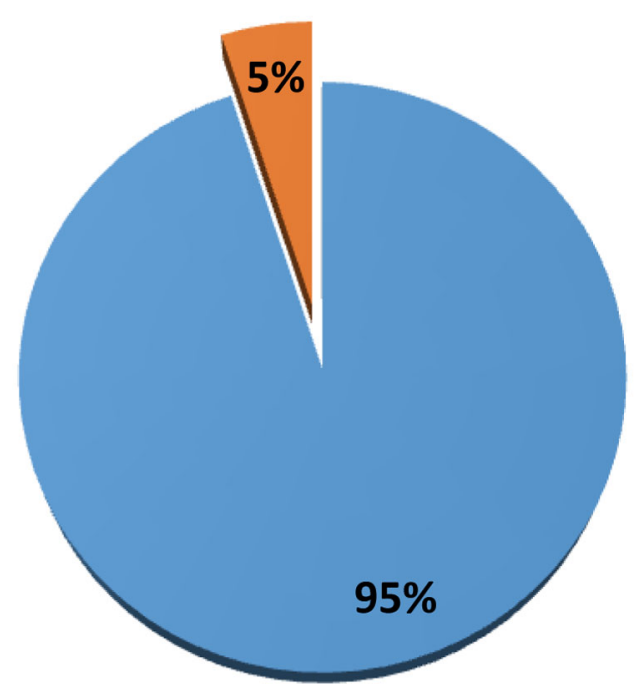

Women 95\% Men 5\%

The majority of respondents were in active working age - 81 (75\%), but $25 \%$ of them worked as dental assistants after retirement - 27 (25\%): (fig. 2.)

Fig. 2. Distribution of dental assistants by age.

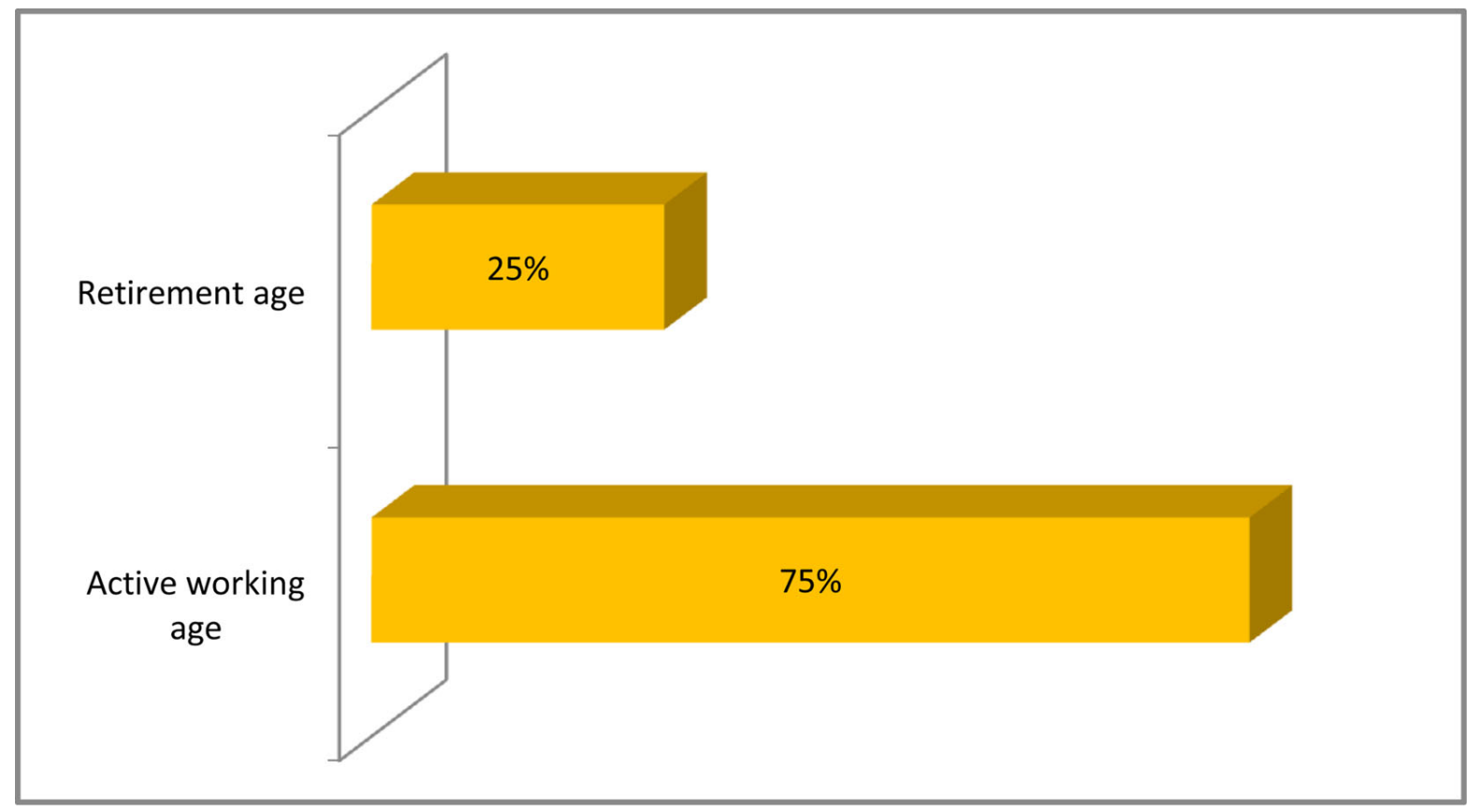

The work experience of the surveyed dental assistants was divided in the following way: 34 (31.48\%) - up to 5 years of apprenticeship in dental practice; 24 (22.22\%) - up to 10 years; $25(23.15 \%)$ - up to 20 years; 15 (13.89\%) up to 30 years and with over 30 years of service as a dental assistant were 10 (9.26\%). (fig. 3.) 
Fig. 3. Distribution of dental assistants according to work experience

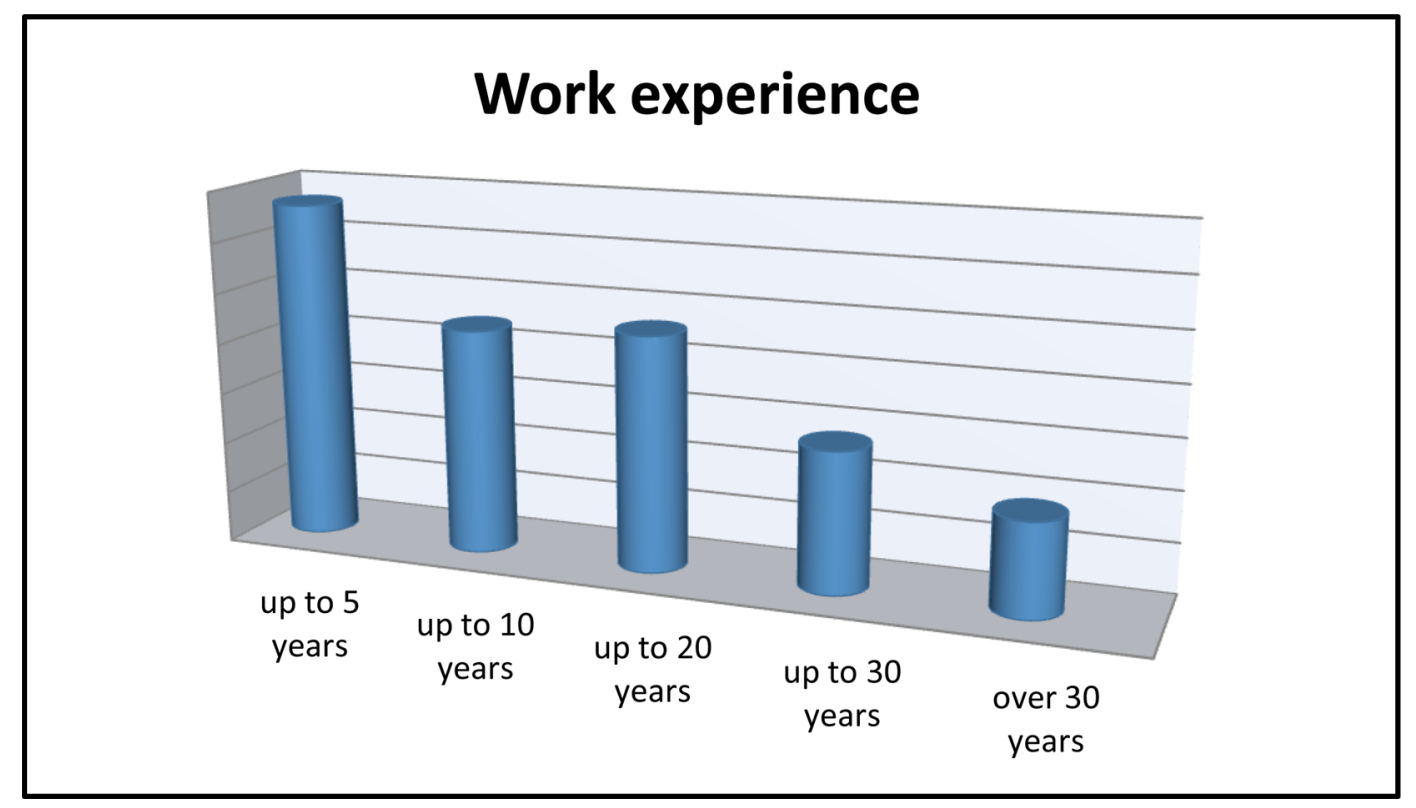

An approximately equal number of inquired persons worked full-time (8 hours per day) - 55 (50.93\%), the remaining part - $53(49.07 \%)$ worked part-time (less than 8 hours per day): (fig. 4.)

Fig. 4.

Working time for dental assistants

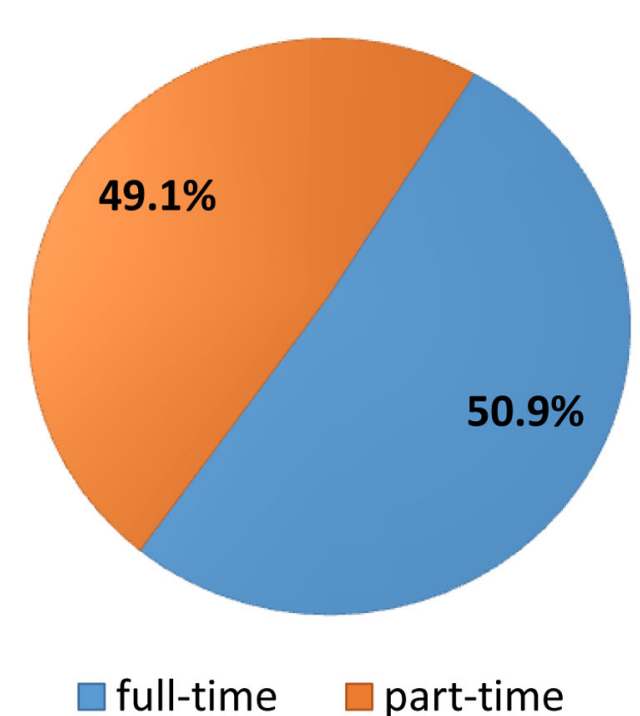

Question No. 4 was related to the location of the workplace. The majority of the inquired - $47(43.52 \%)$ worked in the capital city, $28(25.92 \%)$ in a big city, $24(22.22 \%)$ in small towns, and at least dental assistants worked in villages - only 9 persons (8.33\%): (fig.5.) 
Fig. 5. Location of the workplace

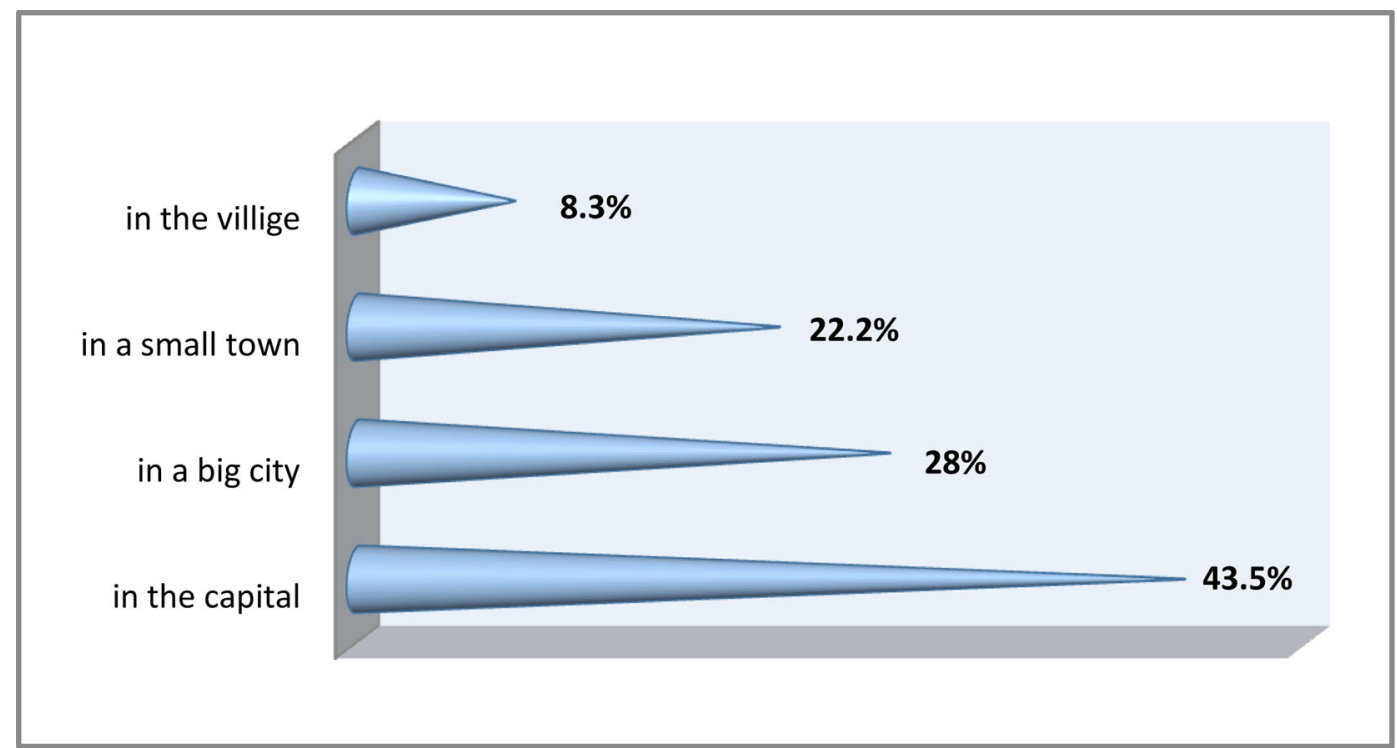

The basic dental care unit in Bulgaria is an individual dental practice. The majority of surveyed - 56 (51.85\%) dental assistants worked in individual practices, the remaining part - $30(27.78 \%)$ worked in group practices and 24 $(22.22 \%)$ - in dental centres. Two of the respondents worked in two different workplaces - individual practice and dental centre: (fig. 6.)

Fig. 6. Types of work places.

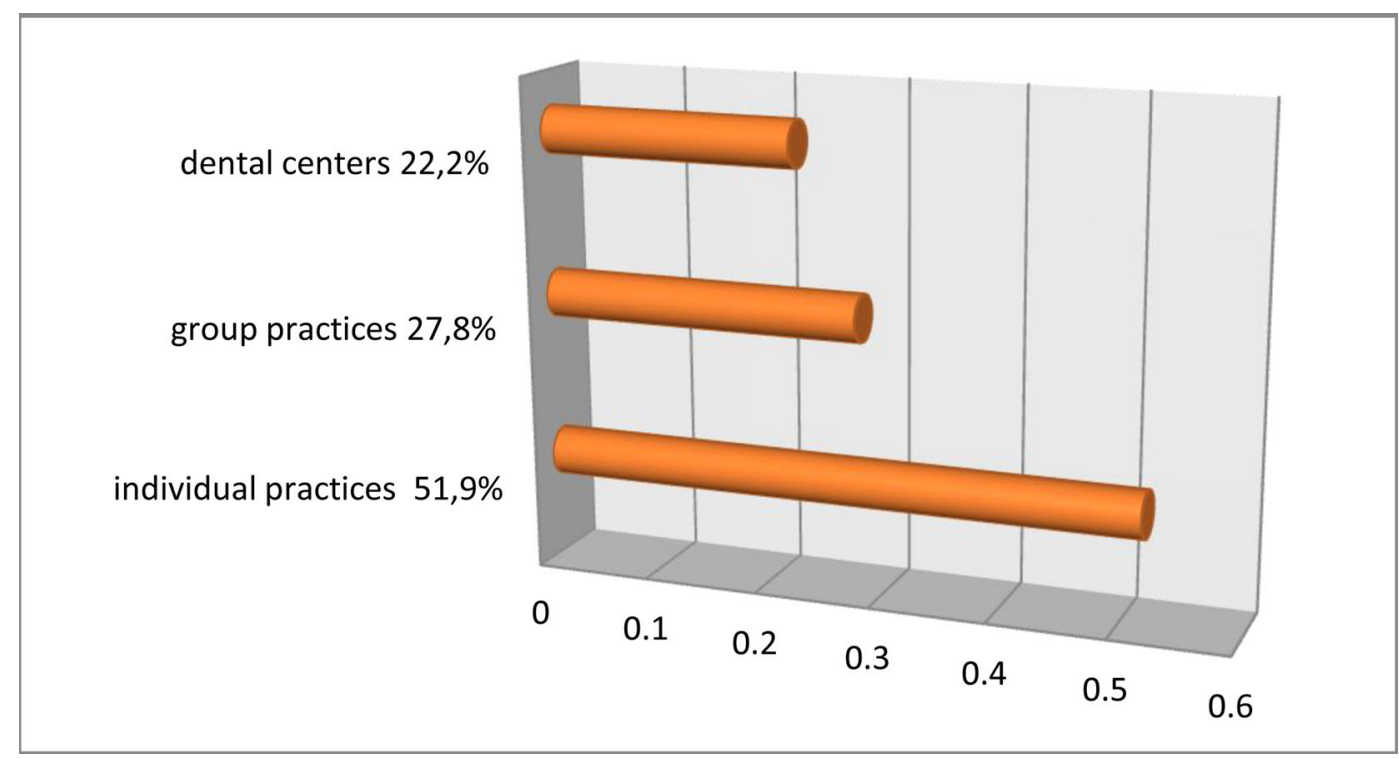

It is very common for dental assistants to work in several practices, especially in part-time work. To the question, "Is the dental practice your single job?" 72 (66.67\%) of respondents said "Yes"; 16 (14.81\%) - "No, I work in more than one practice"; 20 (18.51\%) - "No - I'm still working another, non-medical job": (fig. 7.) 
Fig. 7. Number of assistants' work places

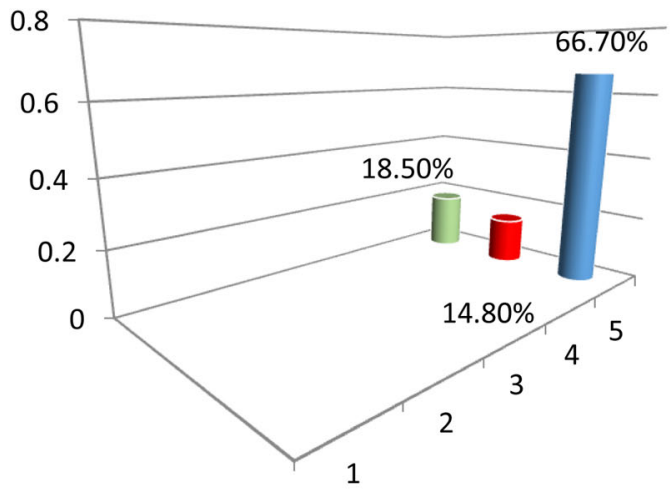

- The dental practice is my single job

- I work in more than one practice

I'm still working another, nonmedical job

In order to analyze the turnover in the organization and the functioning of the team, we included the question, "So far, how many dentists have you worked with?". Only 24 respondents $(22.22 \%)$ answered "Only 1 ", the remaining $84(77.78 \%)$ have worked with "More than one dentist": (fig. 8.)

Fig. 8.

Number of dentists, the dental assistants have worked with

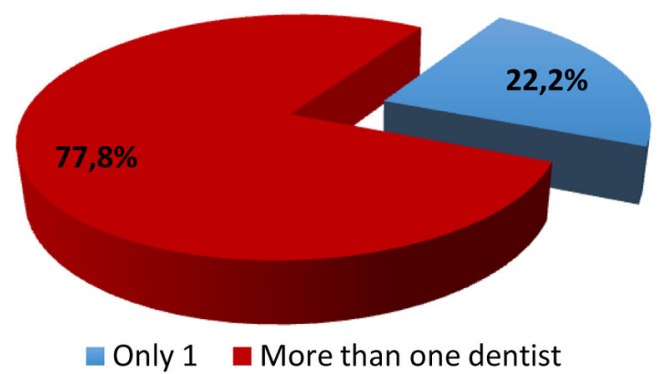

Education is an important element of the knowledge and skills of the worker. In the sample, almost half of respondents - 46 dental assistants (42.60\%) had general medical education, "Dental assistant" education - 35 (32.40\%) and nonmedical education - 27 (25\%): (fig. 9.):

Fig. 9. Type of education of dental assistants

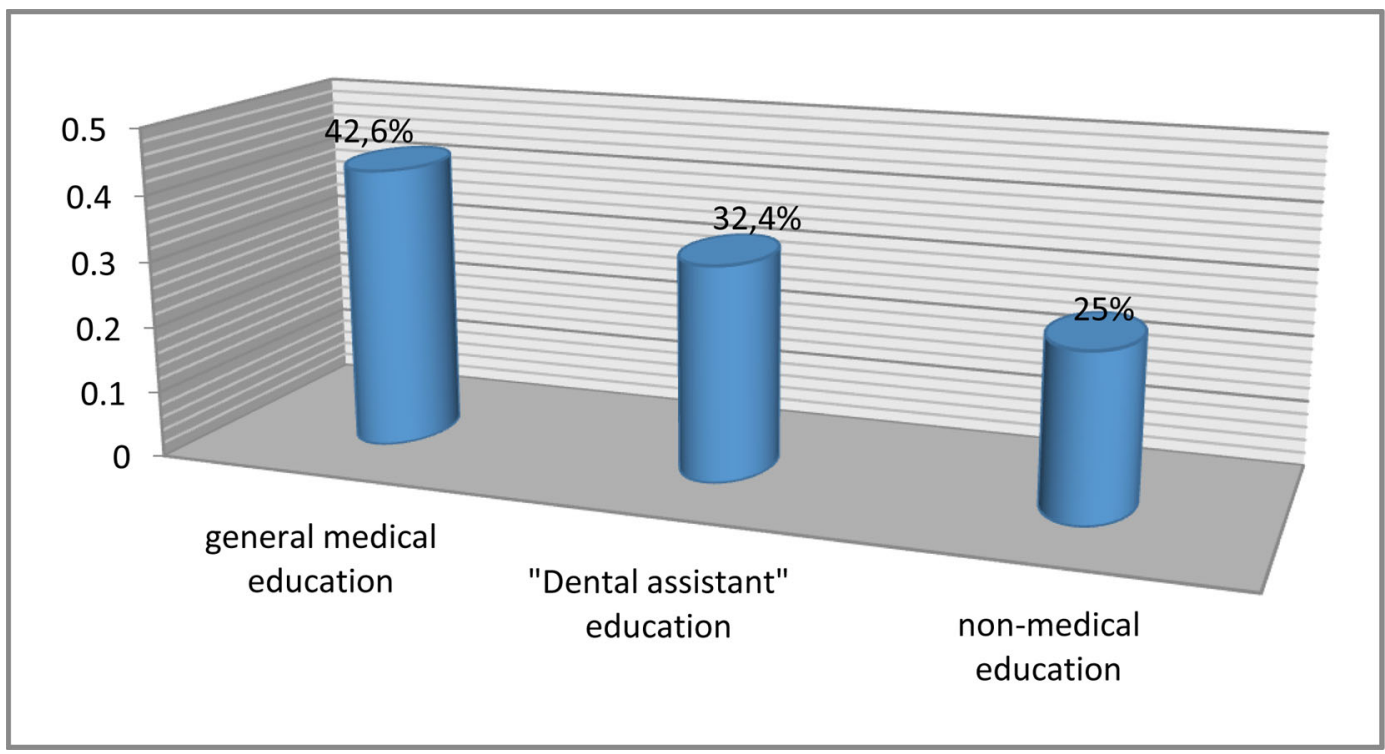

Dental assistants are valuable members of the team. Their duties vary and include: assisting the dentist, disinfection and sterilization of the tools, workplace hygiene, taking care of the patients before and during the treatment, providing instructions for patients' oral care, administrative duties, etc. [8] The answers of the inquired dental assistants for their duties in the dental team are presented in Table 1: 
Table 1. Professional duties of dental assistants

\begin{tabular}{|c|c|c|c|}
\hline Answers & Number & $\% *$ & $\pm \Delta * *$ \\
\hline Assistance in treatmentmanipulations & 108 & 100 & 0 \\
\hline Preparing and arranging the work place & 92 & 85,19 & 6,68 \\
\hline Cleaning, disinfection and sterilization of the tools and the work place & 92 & 85,19 & 6,68 \\
\hline Meeting, lodging, sending out thepatient & 89 & 82,41 & 7,18 \\
\hline Cleaning and sanitation of the premises in practice & 76 & 70,37 & 8,61 \\
\hline Preparation of the work schedule & 49 & 45,37 & 9,39 \\
\hline Maintenance of administrativedocumentation & 25 & 23,15 & 7,96 \\
\hline Financial relationships withpatients & 5 & 4,63 & 3,95 \\
\hline Work in the mouth of the patient & 5 & 4,63 & 3,95 \\
\hline
\end{tabular}

All dental assistants assisted in the treatment process, the majority of them (85.19\%) prepared, arranged and sanitized the workplace, disinfected and sterilized the instruments and sanitized the premises in practice $70.37 \%$ ), welcomed, accommodated and sent out the patients $(82.41 \%)$. Less than half of them had the obligations to prepare the work schedule $(45.37 \%)$, to keep the records $(23.15 \%)$, and only $4.63 \%$ of them performed manipulations in the patient's mouth and settled financial issues with the patients.

The opinion of the dental assistants regarding their contribution to the effective work of the dental team was established by Question No. 17, and the results are shown in table 2:

Table 2. Dental assistants' contribution to effective teamwork

\begin{tabular}{|c|c|c|c|}
\hline Contributions for effective teamwork & Number & $\% *$ & $\pm \Delta * *$ \\
\hline Releasing the doctor from duties below his/her level of competence & 86 & 79,63 & 7,6 \\
\hline Improving the organization of work in the dental office & 63 & 58,33 & 9,3 \\
\hline Shortening the time for treatmentprocedures & 62 & 57,41 & 9,33 \\
\hline The volume of work is increased & 59 & 54,63 & 9,4 \\
\hline The quality of the activity is increased & 59 & 54,63 & 9,4 \\
\hline Patients feel morerelaxed & 57 & 52,78 & 9,42 \\
\hline
\end{tabular}

The majority of respondents said that their assistance released the doctor from a number of duties below his or her level of competence - sanitation, maintenance of aseptic and antiseptic treatment in the office, maintenance of documentation and help for faster and better work and that patients feel more relaxed in the presence of an assistant.

The proper functioning and effectiveness of a professional team depends on a number of factors - the personal and professional qualities of its members and their interpersonal relationships. The opinion of dental assistants on the significance of these factors is reflected in Table 3:

Table 3. Factors contributing to the establishment of efficient dental team

\begin{tabular}{|c|c|c|c|}
\hline Answers & Number & $\% *$ & $\pm \Delta * *$ \\
\hline Mutualrespect & 80 & 74,07 & 8,26 \\
\hline Competent and respecteddentist & 78 & 72,22 & 8,45 \\
\hline Wise and capable dental assistant & 56 & 51,85 & 9,42 \\
\hline Permanent exchange ofinformation & 55 & 50,93 & 9,43 \\
\hline Clearly defined and correctly executed financial relationships & 55 & 50,93 & 9,43 \\
\hline Each team member knows and executes his/her rights and obligations & 54 & 50 & 9,43 \\
\hline Maintaining a relaxed working environment & 54 & 50 & 9,43 \\
\hline Correspondence in the age of the doctor and the assistant & 26 & 24,07 & 8,58 \\
\hline Sharing personal information & 12 & 11,11 & 5,92 \\
\hline
\end{tabular}


In first place $-74.07 \% \pm 8.26$ of the surveyed assistants indicated that the mutual respect among the team members helped to build an effective professional team. The respected personality of the doctor and his/her professional qualities were also essential $(72.22 \pm 8.45 \%)$. More than $50 \%$ of respondents believed that the professional qualities of the assistant, the correct financial relationships, the execution of the rights and obligations of each member of the team, the constant exchange of information and the quiet working environment created good conditions for effective work. According to $24.07 \pm 8.58 \%$ of the respondents, the correlation in the age of the doctor and the assistant was a necessary factor, while $11.11 \pm 5.92 \%$ believed that the friendship between them, in terms of personal information sharing, also contributed to effective teamwork.

\section{DISCUSSION}

The socio-demographic characteristics of a sample of dental assistants in our survey were analogous to the data in literature - the gender structure was analogous to the findings in the study of Durkan C, Belsi A, where $95 \%$ of respondents were women. [9]

In our survey, the respondents in active working age were 81 (75\%), the remaining $27(25 \%)$ were retired, the situation in the Durkan C, Belsi A's study was almost similar $80 \%$ of the dental nurses are between the age of 25 and 44 years.[9]

Labour law in Bulgaria allows dentists to hire for dental assistants' position persons without medical education and to educate and train them in the job. Despite this, many dentists $(45.50 \%)$ believed that dental nurses have to possess Bachelor's degree in medicine. [10]

In some surveys, the authors described as duties of dental nurses expanded functions, such as fluoride prophylaxis, taking X-rays, maintaining conscious sedation etc. [9, $11,12]$

The contribution of dental assistants to better results of dentists' work was proven in the study of M. Simov [10], where $96.70 \%$ of respondents said that the assistance of dental nurse would improve the quality of services. Almost the same number of dentists $-94.93 \%$ believed that teamwork would increase the productivity of dentists' work [2] and decrease stress. [5]
Like in our study, in the study of Hakanen JJ, the dental assistants believed that interpersonal and hierarchical relationships between partners played an important role in building a well-functioning team.[13] In a study of Mindak MT, the inquired dental nurses reported one factor - the lack of praises, which demotivated their work. [14]

\section{CONCLUSION}

The results of the study allowed us to draw the following conclusions:

1. The socio-demographic characteristics of the inquired dental assistants - their distribution by sex and age were similar to the data from the literary sources $-95.4 \%$ women and $4.6 \%$ men, $75 \%$ in active working age and $25 \%$ - pensioners.

2. The socio-professional characteristics of the dental assistants included in the sample were as follows:

- Most of the respondents - $43.52 \%$ worked in the capital city, $25.92 \%$ - in big cities, $22.22 \%$ - in small towns and $8.33 \%$ - in villages.

- The majority of them $-51.85 \%$ worked in individual practices and the rest - in group practices and dental centres.

- With general medical education were $42.60 \%$, with "Dental Assistant" education - $32.40 \%$ and with non-medical education - $25 \%$.

- During the period of their work experience, $77.78 \%$ have worked with more than one dental practitioner.

3. All respondents assisted the dentist in the treatment process, and between 70.37 and $85.19 \%$ of them cleaned, disinfected and sterilized the instruments, the workplace and the premises of the practice. Only $4.63 \%$ have dealt with financial issues with the patient and worked directly in his/ her mouth.

4. Dental assistants were convinced of the benefits of their assistance, with between $79.63 \%$ and $58.33 \%$ believing they relieved the doctor of duties below his or her level of competence, and helped him to work faster and better and contributed to the patient's peace of mind and comfort.

5. The opinion of the respondents for building a wellfunctioning dental team was that both the personal and professional qualities of the team members are essential.

ANNEX 1:
QUESTIONNAIRE
Dear Dental Assistants,
The purpose of this study is to investigate dental assistants' opinion on team work in dental practice.
This research is part of a dissertation.
The voluntary self-filling of the questionnaire will be accepted as a form of individually informed consent to participate in
this survey.
The survey is anonymous. Please tick the correct answers or write your answer to the question
1. You are:
2. Male $\quad$ Your age is:
Active working age


3. Your work experience as a dental assistant is:

* Up to 5 years

* From 6 to 15 years

* From 16 to 30 years

* Over 30 years

4. The location of the practice you are working in is:

* In the capital city

* In a big city

* In a small town

* In a village

5. The type of practice you work in is:

* Individual practice

* Group practice

* Dental Centre

6. Your education is:

* General medical

* Dental assistant

* Non-medical

7. Is dental practice your only job:

* Yes

* No - I work in more than one practice

* No - I'm still working in another profession

8. During your practice with how many doctors you have worked:

9. You are working:

* Full-time - 8 hours / day

* Part time - less than 8 hours/day

10. What obligations do you have in practice:

* Assisting during treatments;

* Preparation of the work schedule;

* Preparing and arranging the workplace;

* Meeting, lodging, assisting and sending out the patient;

* Cleaning, disinfection and sterilization of the workplace and the tools;

- Cleaning and sanitation of the premises in practice;

* Maintaining the administrative documentation of the practice - keeping an ambulatory journal and sheets, preparing reports to RHIF, etc.

* Financial relations with patients;

* Work directly with the patients - polishing of fillings, bleaching, tooth calculus cleaning, laser procedures, thread removal, etc.)

*

11. What are your motives for choosing this profession:

* Interest in dental practice;

* Satisfaction with the nature of work - faster results in achieving aesthetics and function in the oral and maxilla-facial region;

* Less responsibility for the patient's life;

Lack of night shifts, on-call duty, etc.;

* The convenience of placement practice;

* Good financial compensation;

$*$

12. Have your expectations been met for this job:

* Yes

* No

* Partially

13. Does your job bring you satisfaction:

* I am satisfied

* I am partially satisfied

* I am unsatisfied

14. Do you think any dental practitioner should work with support staff:

* Yes

$*$ No

* Recommended

15. Do you think you need further training:

* Yes, from continuing education courses

* My doctor teaches me

16. What additional training do you need:

* On new modern methods and remedies for treatment 
* New requirements on work organization in practice - hygiene requirements, keeping records, etc.

$*$

17. Does your work contribute to the dentist's effective activity:

* Relieves the physician's work by relieving him of a lot of duties below his level of competence - hygiene, maintenance of asepsis and antiseptics in the office, maintenance of documentation

* The treatment time is shortened

* The volume of the activity is increasing

* The quality of the healing work is increased

* Patients feel more relaxed in the presence of a dental assistant

* Improving the organization of work in the dental office

$\star$

18. In your opinion, what is needed to build an effective dental team:

* Competent and respected physician in dental medicine

* A knowledgeable and capable dental assistant

* Each member of the team must know and respect their rights and obligations

* Mutual respect

* Permanent exchange of information

* Keeping a comfortable working environment

* Correspondence in the age of the doctor and the assistant

* Sharing personal information

* Clearly defined and correctly implemented financial relationships

$*$

Thanks for your participation!

\section{REFERENCES:}

1. Hunter T. Assisting: Past, present and future! Dentistry IQ, 2011, Dec.20

2. Dalai DR, Bhaskar DJ, Agali CR, Gupta V, Singh N, Bumb SS. Four Handed Dentistry: An Indispensable Part for Efficient Clinical Practice. Int J Adv Health Sci. 2014 May;1(1):16-20.

3. World Directory of Schools for Dental auxiliaries. WHO, Geneva, 1977, 379.

4. Dental ergonomics and organization of the treatment and diagnostic process. In: Social Medicine, Medical Ethics and Public Dental Health. Editors Yolov T, Yaneva K. Simelpress, Sofia. 2011. pp.210-217. [in Bulgarian]

5. Davidova Il. [Dental assistant an important part of the team]. DEA. 2013 Feb;1:24-25. [in Bulgarian] [nternet]
6. Bojinov PG.[Muscular Skeletal disorders in Dental Practitioners Related to Dental Practice] [dissertation]. Medical University, Sofia. 2014. 172p [in Bulgarian]

7. Tsokov K. [Organization of Dental Practice under Market conditions] [dissertation]. Medical University, Sofia. 2013. 167p. [in Bulgarian]

8. Dental Assistant. ADA. [Internet]

9. Durkan C, Belsi A, Johnson R, Gallagher J. Career choice, pathways and continuing professional development of dental nurses at one institution. Br Dent J. 2012 Jul 27;213(2):E1. [PubMed] [Crossref]

10. Simov MI. [Provision of dental services through teamwork] [dissertation]. Medical University, Varna. 2015. 168p. [in Bulgarian]
11. Jones CM, Walker Al. The role of extended duties dental nurses in applying fluoride varnish for the prevention and control of dental caries. Dent Update. 2010 Oct;37(8):549-52. [PubMed] [Crossref]

12. Tzaribashev K, Topalova S. [Dental nurse with extended functions - the dentists' attitude to her]. Stomatologia (S), 1978; 6:71-74. [in Bulgarian]

13. Hakanen JJ, Perhoniemi R, Bakker AB. Crossover of exhaustion between dentists and dental nurses. Stress Health. 2014 Apr;30(2):110-21. [PubMed] [Crossref]

14. Mindak MT. Service quality in dentistry: the role of the dental nurse. Br Dent J. 1996 Nov 23;181(10):3638. [PubMed] [Crossref]

Please cite this article as: Yaneva-Ribagina K, Antonova C. Dental Assistants in the Teamwork. J of IMAB. 2021 JanMar;27(1):3643-3651. DOI: https://doi.org/10.5272/jimab.2021271.3643

Address for correspondence:

Krassimira Yaneva-Ribagina

Department of Dental Public Health, Faculty of Dental Medicine, Medical University - Sofia,

1, St G. Sofiisku Blvd., 1431 Sofia, Bulgaria.

E-mail: krasimiraribagina@abv.com 